\title{
Mortality Associated With Time in and Out of Buprenorphine Treatment in French Office-Based General Practice: A 7-Year Cohort Study
}

\author{
Julie Dupouy, $M D, P b D^{1,2}$ \\ Aurore Palmaro, $\mathrm{MSc}^{2,3}$ \\ Mélina Fatséas, $M D, P b D^{4,5}$ \\ Marc Auriacombe, $M D^{4,5}$ \\ Joëlle Micallef, $M D, P b D^{6,7}$ \\ Stéphane Oustric, $M D^{1,2}$ \\ Maryse Lapeyre-Mestre, $M D, P b D^{2,3}$ \\ 'Département Universitaire de Médecine \\ Générale, Université Toulouse III Paul \\ Sabatier, Toulouse, France \\ ${ }^{2}$ Inserm UMR1027, Université Toulouse \\ III Paul Sabatier, Faculté de Médecine, \\ Toulouse, France
}

${ }^{3}$ CEIP-Addictovigilance, CIC 1436, Service de Pharmacologie Médicale et Clinique, Faculté de Médecine, Toulouse, France

${ }^{4}$ Pôle Addictologie, CH Charles Perrens et CHU de Bordeaux, Bordeaux Cedex, France

${ }^{5}$ SANPSY (Addiction Psychiatry Team), CNRS USR 3413, Université de Bordeaux, PAC Carreire, Bordeaux Cedex, France

${ }^{6}$ CEIP-Addictovigilance Paca Corse, Service de Pharmacologie Clinique \& Pharmacovigilance, Aix Marseille Université, Marseille, France

${ }^{7}$ Institut de Neurosciences Timone, CNRS 7289, secteur PIICI, Marseille, France

Conflicts of interest: authors report none.

\section{CORRESPONDING AUTHOR}

Julie Dupouy, MD, PhD

Département de Médecine Générale

Faculté de Médecine, 133 route de

Narbonne

31062 Toulouse, France

julie.dupouy@dumg-toulouse.fr

\begin{abstract}
In France, most cases of opioid use disorder are treated with buprenorphine by general practitioners in private practice. Using reimbursement data of a representative sample of the French population, Echantillon Généraliste des Bénéficiaires, we investigated mortality during periods when patients were in and out of treatment in a cohort of 713 new users of buprenorphine having a mean (SD) followup of 4.5 (1.5) years. The mortality rate was 0.63 per 100 person-years $(95 \% \mathrm{Cl}$, 0.40-0.85) overall. In a multivariate Cox regression model, compared with being in treatment, being out of treatment was associated with a markedly increased risk of death (hazard ratio $=29.04 ; 95 \% \mathrm{Cl}, 10.04-83.99$ ). Buprenorphine appears to be a strong protective factor against mortality.
\end{abstract}

Ann Fam Med 2017;15:355-358. https://doi.org/10.1370/afm.2098.

\section{INTRODUCTION}

I n France, methadone and buprenorphine received marketing authorization for medication-assisted treatment for opioid use disorder in 1995 and 1996, respectively. Methadone can be initially prescribed only within a specialized addiction treatment center or a hospital. To facilitate access to opioid maintenance treatment (OMT), buprenorphine can be started in any setting-either specialized centers or office-based general medical practices - as it can be prescribed by all medical doctors without requirement for supplementary education or special licensing. ${ }^{1}$ In contrast to counterparts in other countries, therefore, most patients with opioid use disorder in France are treated with buprenorphine prescribed by general practitioners in private practice, with the medication dispensed exclusively in community pharmacies. ${ }^{2,3}$ The maximum prescription duration for a single prescription is 28 days, with weekly dispensing unless otherwise specified (from daily to every-28-day dispensing). At the start of treatment, the medication may be dispensed daily with supervision by the pharmacist on site. No restriction exists regarding number of patients with opioid use disorder managed by a general practitioner.

Mortality among regular users of heroin is estimated to be 2 deaths per 100 person-years worldwide. ${ }^{4}$ Whereas buprenorphine has been shown to reduce heroin overdose in US and Australian populations ${ }^{5,6}$ and has dramatically done so in France, ${ }^{7}$ few data exist regarding mortality among patients treated with buprenorphine in the context of family medicine. We therefore investigated mortality among outpatients starting OMT with buprenorphine or buprenorphine-naloxone in France, comparing deaths during periods in and out of buprenorphine treatment.

\section{METHODS}

Our data source was the Echantillon Généraliste des Bénéficiaires (EGB), a permanent 1 in 97 representative sample of individuals covered by 
the French Health Insurance System, in 2016, this sample consisted of about 700,000 individuals. ${ }^{8}$ We built a cohort of patients aged 16 to 60 years newly starting buprenorphine or buprenorphine-naloxone therapy between January 2007 and December 2011. All patients had at least 2 years of follow-up (until December 2013), and any subsequently switching to methadone were excluded.

During OMT, patients' drug exposure generally varies widely over time, with a succession of periods in and out of treatment. ${ }^{9}$ To define the different buprenorphine periods (including exposure to buprenorphine, buprenorphinenaloxone, or both), we considered patients to be in buprenorphine treatment if they received regular dispensing of the drug (see Supplemental Appendix, available at http://www.annfammed.org/ content/15/4/355/supp1/DC1/ for a detailed description of treatment period calculations). We considered them to be out of treatment at all other times.

The risk of all-cause mortality was investigated with a multivariate hazard proportional Cox regression model considering buprenorphine treatment periods as time-dependent variables. Other covariates were age; sex; Charlson comorbidity index (predicts mortality risk according to 19 comorbidities); psychiatric diagnoses (coded according to International Classification of Diseases 10th Revision) recorded as chronic diseases (allowing a full coverage by the health insurance system) or recorded during a hospitalization; and dispensed psychoactive medications (opioid analgesics, antiepileptics, antipsychotics, benzodiazepines, antidepressants, drugs for alcohol use disorder). Socioeconomic covariates were an ecologic estimator of social deprivation (FDep, 2008 version $),{ }^{10}$ the status of the beneficiary, and universal insurance coverage (coverage for those unemployed and with low income). Statistical analysis used SAS Guide43 software (SAS Institute, Inc). Details of our methods are described in the Supplemental Appendix.

\begin{tabular}{|c|c|c|c|c|}
\hline \multirow[b]{2}{*}{ Characteristic } & \multirow[b]{2}{*}{$\begin{array}{c}\text { Overall } \\
(\mathrm{N}=713)\end{array}$} & \multicolumn{3}{|c|}{ Vital Status } \\
\hline & & $\begin{array}{c}\text { Alive } \\
(n=684)\end{array}$ & $\begin{array}{l}\text { Deceased } \\
(n=29)\end{array}$ & $\begin{array}{c}P \\
\text { Value }\end{array}$ \\
\hline Sex, No. (\%) & & & & .16 \\
\hline Male & $535(75.0)$ & $510(74.6)$ & $25(86.2)$ & \\
\hline Female & $178(25.0)$ & $174(25.4)$ & $4(13.8)$ & \\
\hline $\begin{array}{l}\text { Age at first buprenorphine claim, mean } \\
\text { (SD), y }\end{array}$ & $32.9(9.0)$ & $32.6(8.9)$ & $41.0(9.2)$ & $<.001$ \\
\hline $\begin{array}{l}\text { Status of beneficiary related to health } \\
\text { insurance affiliation, No. (\%) }\end{array}$ & & & & .21 \\
\hline Insured & $678(95.1)$ & $649(94.9)$ & $29(100.0)$ & \\
\hline Relative & $35(4.9)$ & $35(5.1)$ & $0(0.0)$ & \\
\hline Universal insurance coverage, No. (\%) & $296(41.5)$ & $284(41.5)$ & $12(41.4)$ & .99 \\
\hline $\begin{array}{l}\text { Specialty of first buprenorphine prescriber, } \\
\text { No. (\%) }\end{array}$ & & & & 1.00 \\
\hline General practitioner & $683(95.8)$ & $654(95.6)$ & $29(100.0)$ & \\
\hline Psychiatrist & $10(1.4)$ & $10(1.5)$ & $0(0.0)$ & \\
\hline Other specialist & $9(1.3)$ & $9(1.3)$ & $0(0.0)$ & \\
\hline Not determined & $11(1.5)$ & $11(1.6)$ & $0(0.0)$ & \\
\hline $\begin{array}{l}\text { Practice of first buprenorphine prescriber, } \\
\text { No. (\%) }\end{array}$ & & & & .69 \\
\hline Private practice & $604(84.7)$ & $579(84.6)$ & $25(86.2)$ & \\
\hline Salaried in a private establishment & $92(12.9)$ & $88(12.9)$ & $4(13.8)$ & \\
\hline Not determined & $17(2.4)$ & $17(2.5)$ & $0(0.0)$ & \\
\hline Deprivation index (FDep08ª), mean (SD) & $0.4(1.6)$ & $0.4(1.6)$ & $0.1(1.5)$ & .41 \\
\hline Charlson comorbidity index, ${ }^{\mathrm{b}}$ No. (\%) & & & & .006 \\
\hline 0 & $606(85.0)$ & $587(85.8)$ & $19(65.5)$ & \\
\hline 1 & 85 (11.9) & 78 (11.4) & $7(24.1)$ & \\
\hline$\geq 2$ & $22(3.1)$ & $19(2.8)$ & $3(10.3)$ & \\
\hline $\begin{array}{l}\text { Health insurance coverage for a psychi- } \\
\text { atric disorder, No. (\%) }\end{array}$ & $55(7.7)$ & $51(7.5)$ & $4(13.8)$ & .21 \\
\hline \multicolumn{5}{|l|}{ Hospitalization, No. (\%) } \\
\hline For a psychiatric disorder & $25(3.5)$ & $23(3.4)$ & $2(6.9)$ & .31 \\
\hline For another disorder & $106(14.9)$ & $100(14.6)$ & $6(20.7)$ & .37 \\
\hline Use of opioid analgesics, No. (\%) & $429(60.2)$ & $417(61.0)$ & $12(41.4)$ & .04 \\
\hline Morphine & $39(5.5)$ & $36(5.3)$ & $3(10.3)$ & .21 \\
\hline Codeine, combinations & $212(29.7)$ & $207(30.3)$ & $5(17.2)$ & .13 \\
\hline Dextropropoxyphene, combinations & $133(18.7)$ & $127(18.6)$ & $6(20.7)$ & .77 \\
\hline Tramadol & $134(18.8)$ & $129(18.9)$ & $5(17.2)$ & .83 \\
\hline Tramadol, combinations & $227(31.8)$ & $221(32.3)$ & $6(20.7)$ & .19 \\
\hline \multicolumn{5}{|l|}{ Use of other medications, No. (\%) } \\
\hline Benzodiazepines and similar & $538(75.5)$ & $512(74.9)$ & $26(89.7)$ & .08 \\
\hline Antidepressants & $304(42.6)$ & $286(41.8)$ & $18(62.1)$ & .03 \\
\hline Antipsychotics & $216(30.3)$ & $206(30.1)$ & $10(34.5)$ & .62 \\
\hline Antiepileptics & $107(15.0)$ & $100(14.6)$ & $7(24.1)$ & .18 \\
\hline Drugs for alcohol dependence & $72(10.1)$ & $69(10.1)$ & $3(10.3)$ & .96 \\
\hline
\end{tabular}




\section{RESULTS}

Among 1,076 patients starting OMT from 2007 to 2011, a total of 713 patients received buprenorphine or buprenorphine-naloxone. This cohort had 3,219.4 person-years of follow-up, with a mean of 4.5 years (SD 1.5). For 588 patients $(82.5 \%)$, the first buprenorphine prescriber was a general practitioner in private practice. Patients were treated for a median duration of 680 days (interquartile range, 116-1,292) corresponding to 3 treatment periods (interquartile range, 1-6). Twentyfive patients (3.5\%) were hospitalized for a psychiatric disorder and 106 (14.9\%) for another disease; the mean duration of hospitalization was 7.0 days (SD 9.8).

Twenty-nine patients (4.1\%) died during follow-up (none during hospitalization). Table 1 describes the characteristics of cohort patients overall and according to their vital status. The mortality rate was 0.63 per 100 person-years ( $95 \% \mathrm{CI}, 0.40-0.85$ ) in our study cohort, compared with 0.24 per 100 person-years (95\% CI, 0.24-0.25) for other individuals aged 16 to 60 years from the same database during the same period.

In the multivariate analysis, patients had an elevated risk of death if they were older than 40 years as compared with younger than 30 years (hazard ratio $=3.94$; 95\% CI, 1.45-10.69) and especially when they were out of buprenorphine treatment as compared with in treatment (hazard ratio $=29.04 ; 95 \% \mathrm{CI}, 10.04-83.99)($ Table 2). Opioid analgesic use was associated with a lower risk of death (hazard ratio $=0.37 ; 95 \% \mathrm{CI}, 0.18-0.79$ ). ratio of 29, which is more than 10 -fold higher than that previously reported in a meta-analysis (pooled hazard ratio of 2.38 for out-of-treatment periods ${ }^{4}$ ). Most previous studies, however, were conducted among patients treated with methadone. We might also interpret this result cautiously because of the low number of deaths observed during our 7-year study period.

Pain is recognized as interacting with opioid use disorders, with a lower effectiveness of OMT and a higher risk of relapse in patients reporting pain. ${ }^{12}$ The association of opioid analgesics with reduced mortality might therefore be interpreted as an indicator of better pain management.

Medications dispensed in hospital settings are not available in the EGB database. For some patients, the duration of buprenorphine treatment could have been underestimated, and they may have received the medication during hospitalization when they were considered to be out of treatment. This bias seems limited, however, given the low number of days of hospitalization during the study period.

To the best of our knowledge, this study is the first to describe the association of exclusive buprenorphine maintenance with mortality among patients in ambulatory practice. In this French-specific context, being in treatment vs out of treatment was associated with a reduction of at least 10 -fold in the risk of death. These findings should encourage physicians to avoid interrupting buprenorphine treatment and encourage patients to continue treatment as long as it is needed.

\section{DISCUSSION}

There is a lack of data regarding the association of buprenorphine as sole OMT with mortality in office-based general medical practice. We found that compared with the French general population, the mortality rate for patients initiating buprenorphine treatment was 3 times higher; at the same time, it was lower than that observed in previous studies among dependent or regular users of opioids. ${ }^{4}$ In a recent study performed in Australia, where buprenorphine can be prescribed only by registered physicians, the mortality rate for buprenorphine-treated patients was 0.4 per 100 person-years, ${ }^{11}$ which is consistent with our findings.

Our study showed that during buprenorphine OMT, being out of treatment was associated with sharply elevated mortality risk, with a hazard
Table 2. Factors Associated With Mortality Among Outpatients With Opioid Use Disorder Treated With Buprenorphine, in Univariate and Multivariate Cox Models

\begin{tabular}{|c|c|c|c|c|}
\hline Factor & $\begin{array}{c}\text { Crude } \\
\text { Hazard Ratio } \\
(95 \% \mathrm{Cl})\end{array}$ & $\begin{array}{c}P \\
\text { Value }\end{array}$ & $\begin{array}{l}\text { Adjusted } \\
\text { Hazard Ratio } \\
(95 \% \mathrm{Cl})\end{array}$ & $\begin{array}{c}P \\
\text { Value }\end{array}$ \\
\hline $\begin{array}{l}\text { Buprenorphine treat- } \\
\text { ment: out vs in }\end{array}$ & $33.22(11.56-95.50)$ & $<.001$ & $29.04(10.04-83.99)$ & $<.001$ \\
\hline \multicolumn{5}{|l|}{ Age, y } \\
\hline$<30$ & Ref & & Ref & \\
\hline $30-40$ & $1.37(0.42-4.48)$ & .61 & $1.08(0.33-3.54)$ & .90 \\
\hline$>40$ & $6.47(2.40-17.43)$ & $<.001$ & $3.94(1.45-10.69)$ & .007 \\
\hline \multicolumn{5}{|l|}{$\begin{array}{l}\text { Charlson comorbidity } \\
\text { index }\end{array}$} \\
\hline 0 & Ref & & - & - \\
\hline 1 & $2.68(1.23-6.37)$ & .03 & & \\
\hline$\geq 2$ & $4.75(1.41-16.08)$ & .01 & & \\
\hline Sex: female vs male & $0.49(0.17-1.41)$ & .18 & - & - \\
\hline \multicolumn{5}{|l|}{ Medication use } \\
\hline Opioid analgesics & $0.40(0.19-0.83)$ & .01 & 0.37 (0.18-0.79) & .01 \\
\hline Antidepressants & $2.06(0.97-4.37)$ & .06 & - & - \\
\hline $\begin{array}{l}\text { Benzodiazepines } \\
\text { (and similar) }\end{array}$ & $2.61(0.79-8.62)$ & .12 & - & - \\
\hline
\end{tabular}


To read or post commentaries in response to this article, see it online at http://www.AnnFamMed.org/content/15/4/355.

Key words: opioid-related disorders; opioid maintenance treatment; buprenorphine; mortality; private practice; primary care; ambulatory care; cohort studies

Submitted December 8, 2016; submitted, revised, April 25, 2017; accepted May 9, 2017.

Previous presentations: Société Française de Pharmacologie; April 19-21, 2016; Nancy, France; Ateliers d'addictovigilance; October 17-18, 2016; Biarritz, France; and Congrès du Collège National des Généralistes Enseignants; November 23-25, 2016; Grenoble, France.

Supplementary materials: Available at http://www.AnnFamMed. org/content/15/4/355/suppl/DC1/

\section{References}

1. Fatseas M, Auriacombe M. Why buprenorphine is so successful in treating opiate addiction in France. Curr Psychiatry Rep. 2007; 9(5):358-364.

2. Lapeyre-Mestre M, Llau M-E, Gony M, et al. Opiate maintenance with buprenorphine in ambulatory care: a 24-week follow-up study of new users. Drug Alcohol Depend. 2003;72(3):297-303.

3. Observatoire Française des Drogues et des Toxicomanies. Les traitements de substitution aux opiacés: données récentes. Tendances. 2014: 94. http://www.ofdt.fr/publications/collections/periodiques/ lettre-tendances/les-traitements-de-substitution-aux-opiaces-donneesrecentes-tendances-94-octobre-2014/. Accessed Apr 25, 2017.
4. Degenhardt L, Bucello C, Mathers B, et al. Mortality among regular or dependent users of heroin and other opioids: a systematic review and meta-analysis of cohort studies. Addiction. 2011;106(1):32-51.

5. Schwartz RP, Gryczynski J, O'Grady KE, et al. Opioid agonist treatments and heroin overdose deaths in Baltimore, Maryland, 19952009. Am J Public Health. 2013;103(5):917-922.

6. Bell J, Trinh L, Butler B, Randall D, Rubin G. Comparing retention in treatment and mortality in people after initial entry to methadone and buprenorphine treatment. Addiction. 2009;104(7):1193-1200.

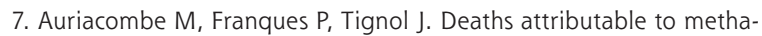
done vs buprenorphine in France. JAMA. 2001;285(1):45.

8. Moulis G, Lapeyre-Mestre M, Palmaro A, Pugnet G, Montastruc J-L, Sailler $\mathrm{L}$. French health insurance databases: What interest for medical research? Rev Med Interne. 2015;36(6):411-417.

9. Dupouy J, Bez J, Barsony J, Oustric S, Lapeyre-Mestre M. [Opiate substitution treatment's cycles in a five-year followed-up cohort in ambulatory practice]. Therapie. 2013;68(3):155-161.

10. Windenberger F, Rican $S$, Jougla E, Rey G. Spatiotemporal association between deprivation and mortality: trends in France during the nineties. Eur J Public Health. 2012;22(3):347-353.

11. Kimber J, Larney S, Hickman M, Randall D, Degenhardt L. Mortality risk of opioid substitution therapy with methadone versus buprenorphine: a retrospective cohort study. Lancet Psychiatry. 2015;2(10):901-908.

12. Bounes V, Palmaro A, Lapeyre-Mestre M, Roussin A. Long-term consequences of acute pain for patients under methadone or buprenorphine maintenance treatment. Pain Physician. 2013;16(6): E739-E747. 